\title{
H.761 Support of an SVG Media Type
}

\author{
Alan L. V. Guedes \\ TeleMídia - PUC-Rio \\ alan@telemidia.puc-rio.br
}

\begin{abstract}
The H.761 standard defines that the NCL media object that is required in a Ginga-NCL implementation is the hypertext markup language (HTML)-based media object. Such HTML media object considerable use of memory and data transmission. Therefore, it is useful for devices with considerable memory and with a broadband connection. However, it is not recommended for scenarios with low bitrate and contrast memory, such as the digital radio device. In such cases, the NCL application used data should be minimum. For such scenarios, the use of graphic media, such as png and jpg, can consume considerable data. We propose that an SVG engine should also be required to support such cases.
\end{abstract}

\section{KEYWORDS}

NCL, Ginga, SVG

\section{BACKGROUND}

The H.761[1] standard defines that "NCL media object that is required in a Ginga-NCL implementation is the hypertext markup language (HTML)-based media object" Such HTML media object use considerable amount of memory and data transmission. Therefore, it is useful for devices with considerable memory and with a broadband connection. However, it is not recommended for scenarios with low bit-rate and contrast memory, such as the digital radio device. In such cases, the NCL application used data should be minimum. For such scenarios, the use of graphic media, such as png and jpg, can consume considerable data.

\section{PROPOSAL}

Support Vector Graphics SVG Tiny $1.2^{1}$. More precisely, we propose support of the mime type "image/svg $+\mathrm{xml}$ " for <media> content.

\section{USE CASE}

The following codes present the SVG code and NCL example using it, respectively.

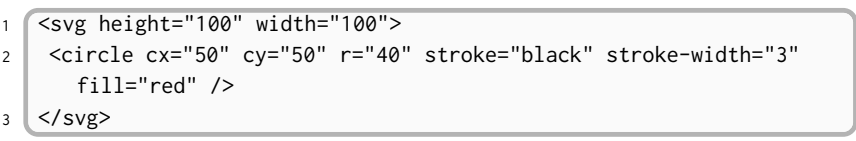

Listing 1: SVG code fragment

In: Future of Interactive Television Workshop (V WTVDI), Rio de Janeiro, Brasil. Anais Estendidos do Simpósio Brasileiro de Sistemas Multimídia e Web (WebMedia). Porto Alegre: Sociedade Brasileira de Computação, 2019.

ISSN 2596-1683
}

\author{
Sergio Colcher \\ Informatics Departament - PUC-Rio \\ colcher@inf.puc-rio.br \\ <property name="zIndex" value $=" 0 " />$ \\ $<$ property name='bounds' value=' $0 \%, 0 \%, 50 \%, 50 \%$ ' /> \\ $</$ media $>$ \\ $</$ body $>$ \\ $</$ ncl $>$ \\ Listing 2: NCL code fragment with problems.

\section{REFERENCES} \\ [1] ITU. 2009. H.761: Nested Context Language (NCL) and Ginga-NCL for IPTV Services. \\ Technical Report. ITU, Geneva, Switzerland. https://www.itu.int/rec/T-REC-H. \\ 761
}

